\title{
Prophylactic ondansetron does not reduce the inci- dence of itching induced by intrathecal sufentanil
} [L'administration prophylactique d'ondansétron ne réduit pas l'incidence de prurit induit par le sufentanil intrathécal]

Beverly Waxler MD, Shirley A. Mondragon mS CRNA, Sonal N. Patel MD, Kochuthresia Nedumgottil MD

Purpose: Postoperative itching after intrathecal (IT) narcotics may be a difficult and important problem for both the anesthesiologist and the patient in the postanesthetic care unit. Since some studies have reported success in preventing itching with ondansetron, we designed a prospective, randomized, double-blinded, and controlled study to test whether prophylactic iv ondansetron effectively reduces the incidence of IT sufentanil-induced pruritus.

Methods: Thirty-four patients (ASA I-III, age I8-74 yr) underwent ambulatory surgery after spinal anesthesia with IT lidocaine (15-100 mg) and IT sufentanil $(10 \mu \mathrm{g})$. The patients were randomized into two groups to receive iv either $4 \mathrm{~mL}$ saline $(n=13)$ or $8 \mathrm{mg}$ ondansetron $(n=2 \mathrm{I})$ before the IT injection. The incidence of pruritus and other variables was recorded. Pruritus scores were obtained with a verbal analogue score with 0 meaning none and 10 the worst itching that the patient could imagine. Statistical difference was assumed if $P<0.05$.

Results: Ondansetron did not reduce the incidence of pruritus (77 vs $81 \%)$ compared to placebo $(P=1.000)$. The pruritus scores (4.4 vs 3.6) of the two groups were not significantly different $(P=$ 0.670).

Conclusions: There are contradictory findings in the literature regarding the effectiveness of ondansetron in preventing narcoticinduced itching. Although some studies have indicated that ondansetron could prevent this side effect of IT narcotics, a recent report suggested that ondansetron is not effective in preventing narcotic-induced itching (sufentanil-morphine) after a Cesarean section. In the present study we obtained similar, negative results.
Objectif : Le prurit postopératoire induit par l'administration intrathécale (IT) de narcotiques est un problème important pour l'anesthésiologiste et le patient en salle de réveil. Certaines études ont montré que l'ondansétron prévenait le prurit. Notre étude prospective, randomisée, contrôlée et à double insu voulait vérifier si l'administration iv préventive d'ondansétron réduit effectivement l'incidence de prurit induit par le sufentanil IT.

Méthode : Trente-quatre patients (ASA I-III, de 18 à 74 ans) ont subi une intervention chirurgicale ambulatoire sous rachianesthésie avec de la lidocaïne IT (15-100 mg) et du sufentanil IT (10 $\mu \mathrm{g})$. Les patients, randomisée en deux groupes, ont reçu soit $4 \mathrm{~mL}$ de solution saline iv ( $n=13)$, soit $8 \mathrm{mg}$ d'ondansétron $(n=21$ ) avant l'injection IT. L'incidence de prurit et d'autres variables a été notée. Les scores de prurit ont été obtenus par une échelle verbale analogique où 0 n'indiquait aucun prurit et 10, le pire prurit imaginable. On supposait une différence statistique si $P<0,05$.

Résultats : L'ondansétron, comparé au placebo, n'a pas réduit l'incidence de prurit (77 vs $81 \%, P=1,000)$. Le prurit $(4,4$ vs 3,6$)$ des patients des deux groupes n'était pas significativement différent ( $P=$ 0,670).

Conclusion : Des résultats contradictoires découlent de publications sur l'efficacité de l'ondansétron dans la prévention du prurit induit par les narcotiques. Certaines études ont indiqué que l'ondansétron pouvait prévenir cet effet secondaire des narcotiques IT, mais un article récent montre qu'il n'est pas efficace (avec sufentanil-morphine) après une césarienne. Nos résultats négatifs sont similaires.

From the Department of Anesthesiology and Pain Management, John H. Stroger Jr. Hospital of Cook County, Chicago, Illinois, USA. Address correspondence to: Dr. Beverly Waxler, Division of Postanesthesia Care, Department of Anesthesiology and Pain Management, John H. Stroger Jr. Hospital of Cook County, 1901 West Harrison Street, Chicago, IL 60612, USA. Phone: 312-864-2140; Fax: 312-864-9544; E-mail: 74731.463@compuserve.com

Financial support: no extramural support. Accepted for publication January 21, 2004.

Revision accepted April 14, 2004. 
$\mathrm{P}$ OSTOPERATIVE itching is a difficult and important problem for both the anesthesiologist and the patient in the postanesthetic care unit (PACU). Patents who suffer from itching often complain bitterly. Itching after intrathecal (IT) opioids is an undesirable side effect of opioids ${ }^{1-3}$ which can develop with a frequency ranging between 20 and $80 \% .^{2,4}$

The mechanisms causing pruritus (and the resultant scratching) are complex ${ }^{2,3,5}$ and may involve central or peripheral mechanisms. Central mechanisms of opioid-induced pruritus (either systemically or regionally) are more important clinically than peripheral mechanisms. Both central opiate and serotonin receptors are involved. Naloxone (a $\mu$ antagonist) is effective against itching from IT or epidural morphine but may increase pain. ${ }^{2,3} \mathrm{Hl}$ blockers are not effective against centrally mediated narcotic-induced itching. ${ }^{3}$

Since some studies ${ }^{6-8}$ have reported success with preventing itching with $i v$ ondansetron, we questioned whether ondansetron would prevent pruritus in patients receiving IT sufentanil.

\section{Methods}

The Institutional Review Board approved the study, and written consent was obtained from each patient. The protocol was a prospective, randomized, doubleblinded, controlled study of the incidence and severity of itching after IT lidocaine and sufentanil. Thirty-four ASA physical status I to III patients, 18 to $74 \mathrm{yr}$ old, were scheduled for various outpatient surgical procedures under spinal anesthesia with lidocaine (15-100 $\mathrm{mg}$, in $7.5 \%$ dextrose in water, as needed for the procedure) and sufentanil $(10 \mu \mathrm{g})$. Patients were randomized into two groups (with Statmate software, Graph Pad, San Diego, CA, USA) to receive iv either $4 \mathrm{~mL}$ saline $(n=13)$ or $8 \mathrm{mg}$ ondansetron $(n=21)$ before IT injection.

One investigator prepared the $i v$ solutions of ondansetron or saline. The patient, the anesthesiologist [who administered the iv injection and evaluated the patient in the operating room, (OR)], and another investigator (an anesthesiologist who evaluated the patient in the PACU) were all blinded to whether the patient received $i v$ ondansetron or placebo. The study excluded patients with: ages younger than $18 \mathrm{yr}$ or older than $75 \mathrm{yr}$, a history of an allergic reaction to opioids, current opioid use or abuse, psychiatric impairment, refusal of spinal anesthesia or participation in the study, coagulopathy, infection at the site of the proposed IT injection, symptoms of increased intracranial pressure, current pregnancy, a history of an adverse or allergic reaction to ondansetron, any dis- ease associated with pruritus, and any significant cardiac, liver, or neurological disease.

The patient was placed in a sitting position and, before the IT injection, received a slow iv injection of $4 \mathrm{~mL}$ of normal saline or $4 \mathrm{~mL}(8 \mathrm{mg})$ of ondansetron. Spinal anesthesia was administered in the sitting position using a 25 -gauge pencil point needle at the L3-4 intervertebral space with a sterile technique. After free flow of clear cerebrospinal fluid, the anesthetic mixture was injected at the rate of $1 \mathrm{~mL}$ per five seconds. Immediately after, the patient was placed in the supine or prone position. Three minutes later, each patient was assisted into the surgical position. Patients were monitored for the onset and level of sympathetic, motor and sensory blockade. The operation proceeded when adequate sensory and motor blocks were obtained.

In the OR, doses of 1 to $2 \mathrm{mg}$ of midazolam were titrated $i v$ to relieve anxiety. No iv narcotic was used in the OR unless the patient complained that he/she was uncomfortable [in which case, incremental doses of fentanyl $(25 \mu \mathrm{g})$ were given until the patient felt comfortable]. No other $i v$ sedation medications were used in the OR. No ketorolac was used in the OR.

Specific variables were evaluated every $15 \mathrm{~min}$ in the OR or PACU for the first $90 \mathrm{~min}$, then every 30 $\mathrm{min}$. The following variables were evaluated: incidence, location and severity [verbal analogue score (VAS)] of pruritus, postoperative pain, or any other problems. Pain and pruritus scores were obtained with VAS with 0 meaning none and 10 the worst pain or itching that the patient could imagine. Pruritus was treated with diphenhydramine first and then naloxone (if necessary) if the patient requested medication to relieve the itching.

From the OR, all patients went to the PACU. In the PACU, $30 \mathrm{mg}$ of ketorolac iv were given if the patient complained of pain and there were no contraindications. Also, incremental doses of fentanyl were given to patients with pain scores greater than 4 . The patient was discharged (from the PACU) when he/she met our standard criteria: 1) the oxygen saturation (by pulse oximetry) on room air was greater than $92 \% ; 2$ ) the patient was able to breathe and cough freely; 3 ) the systolic blood pressure was $20 \%$ of the preanesthetic level; 4) the patient was fully awake; 5 ) the patient was able to stand and walk [to go to the same day surgery (SDS) unit, and home]; 6) the patient was free of itching (or pain) or did not request further medication for mild itching (or discomfort).

Power analysis was performed with Statmate software (GraphPad) to calculate the minimum number of patients in each group. A power analysis showed that 
the minimum number of patients for an $80 \%$ power was 35 patients per group to detect a $25 \%$ decrease in the incidence of pruritus (if the incidence was expected to be $33 \%$ ). We chose a value on the lower end of the expected range (20 to $80 \%$ ). Our original plan was to study 40 patients in each group (to accommodate for patient "drop out"). However, the actual incidence of pruritus was much higher than expected so that a post hoc analysis showed that sample size was appropriate to exclude a type II error. Values are reported as mean $\pm \mathrm{SD}$ or as percentage. Nonparametric data were analyzed with Fisher's exact test or Mann-Whitney $U$ test as appropriate. Parametric data were analyzed with an unpaired Student's $t$ test. All tests were two tailed. Statistical difference was assumed if $P<0.05$.

\section{Results}

The ages, gender, height, and type of outpatient surgery (Table) were similar in the two groups, but patients in the saline group were heavier than in the ondansetron group $(P=0.024)$. The incidence of pruritus was not significantly different in the two groups ( 77 vs $81 \%, P=1.000$, Table). Post hoc power analysis showed a $95 \%$ power to see a change in the incidence from $80 \%$ to $42 \%$. The mean maximal pruritus score (VAS) in the ondansetron group $(3.6 \pm 2.9)$ was not statistically different from that in the saline group (4.4 \pm 3.4 ). Sixty-two percent of patients in the saline group required additional medication (diphenhydramine or naloxone or both) for pruritus compared to $33 \%$ in the ondansetron group (not statistically different, $P=$ 0.1596). Three patients (two from the saline group and one from the ondansetron group) needed naloxone ( $P$ $=$ NS). Pain scores were not different between groups.

In the OR, all patients (except five) required 2 to 4 mg midazolam $i v$ for anxiety (with three needing none or $1 \mathrm{mg}$ and two others needing more than $4 \mathrm{mg}$ ). In the ondansetron group, one patient needed a small dose of $i v$ fentanyl $(25 \mu \mathrm{g})$ in the OR. After discharge from the PACU, all patients (except for one patient from each group) went to the SDS unit (and then home). These two patients had urological procedures. Follow-up after leaving the PACU was impossible in $24 \%$ of patients.

\section{Discussion}

Many patients developed postoperative itching as a side effect of the IT narcotic. Since ondansetron has been reported to be effective in treating pruritus induced by IT morphine or fentanyl, ${ }^{6-8}$ we designed this study to test whether iv ondansetron $(8 \mathrm{mg})$ reduces the incidence of itching induced by IT lido-
TABLE Demographic and recovery variables

\begin{tabular}{lll}
\hline & Saline & Ondansetron \\
\hline Number $(n)$ & $n=13$ & $n=21$ \\
Sex $(\mathrm{M} / \mathrm{F})$ & $13 / 0$ & $18 / 3$ \\
Mean age $(\mathrm{yr})$ & $41 \pm 10$ & $39 \pm 14$ \\
Mean height $(\mathrm{cm})$ & $176 \pm 7$ & $172 \pm 7$ \\
Mean weight $(\mathrm{kg})$ & $88 \pm 14$ & $77 \pm 11^{*}$ \\
Pruritus (\%) & 77 & 81 \\
Mean maximal pruritus score (VAS) & $4.4 \pm 3.4$ & $3.6 \pm 2.9$ \\
Medication needed for pruritus (\%) & 62 & 33 \\
Mean maximal pain score (VAS) & $1.3 \pm 2.6$ & $1.4 \pm 3.1$ \\
iv narcotic needed in PACU (\%) & 38 & 24 \\
Operation (rectal/other) & $7 / 6$ & $17 / 4$ \\
\hline
\end{tabular}

VAS $=$ verbal analogue score; PACU $=$ postanesthetic care unit. ${ }^{*} P<0.05$, values are mean $\pm S D$ unless otherwise specified.

caine $(15-100 \mathrm{mg})$ and sufentanil $(10 \mu \mathrm{g})$ in patients undergoing ambulatory surgery. Our results show that the overall incidence of itching was not decreased by ondansetron.

Most patients had either mild pruritus (not requiring medication) or moderate pruritus (requiring diphenhydramine but not naloxone). Only three patients (two in the saline group) had severe pruritus (not responding to diphenhydramine and needing naloxone). However, $62 \%$ of patients (in the saline group) required additional medication for pruritus compared to $33 \%$ (in the ondansetron group), but the difference was not statistically different.

Pruritus (itching) is a sensation ${ }^{2,3}$ which often leads to an action (scratching). In the present study, we asked patients specifically about itching and the incidence of this adverse event in patients exposed to IT sufentanil was approximately $80 \%$, in contrast to $50 \%$ in a similar study ${ }^{4}$ by our group. However, the two studies may not be entirely comparable because the explanations given to the patients were different. In the present study, patients were told that the main purpose of the trial was to test whether ondansetron would prevent itching after spinal anesthesia with lowdose lidocaine and IT sufentanil. In our previous study, ${ }^{4}$ patients were told that the main purpose of the study was to compare recovery after two different techniques for spinal anesthesia, warning about possible complications including pruritus. Since pruritus is a sensation, ${ }^{2,3}$ its perception may also be influenced by the explanation of the project to the patients. Therefore, we feel the wide range of reported incidences of IT narcotic-induced pruritus may, in part, be caused by patient perception of the trial objectives. 
Postoperative itching after IT narcotics is an undesirable side effect of anesthesia and is caused by several, complex mechanisms., ${ }^{2,3,5}$ Current research indicates that central causes of pruritus are more important than peripheral ones. ${ }^{2}$ IT opioid-induced itching may be related to the cephalad spread of the drug in the cerebrospinal fluid and its action on both $\mu$ receptors (in the medulla), ${ }^{5,9,10}$ and central serotonin type 3 receptors (in the spinal cord and medulla). ${ }^{11,12}$ Therefore, opioids that do not cause peripheral histamine release can still cause itching. ${ }^{2,3}$ Opioids administered (both systemically and regionally) reach central neural centres. Opioids may also act on another portion of the brain (probably midbrain) to reduce itching. ${ }^{10,13} \mathrm{~A}$ recent hypothesis ${ }^{14}$ proposes that there are itching-specific neurons in the spinothalamic tract, which respond to histamine. Ondansetron may not have prevented patients in this study from experiencing itching because of three reasons: 1) pruritus is the end result of multiple mechanisms; 2) IT sufentanil may produce more pruritus than other IT opioids; ${ }^{2} 3$ ) ondansetron may not have reached the appropriate central serotonin receptors.

Since IT opioids do not produce itching by the release of histamine, ${ }^{3} \mathrm{Hl}$ blockers (like diphenhydramine) have little effect on centrally-induced itching. ${ }^{3}$ However, diphenhydramine produces a sedative effect which may be helpful. ${ }^{3}$ Naloxone (a $\mu$ antagonist) is often effective against IT or epidural opioidinduced itching but can increase postoperative pain. ${ }^{2,3}$ Nalbuphine (a $\mu$ agonist-antagonist) and droperidol ${ }^{15}$ have also been used to prevent pruritus and nausea. Ondansetron (a serotonin type 3 receptor antagonist) is also effective in treating pruritus induced by epidural or IT morphine. Borgeat and Stirnemann ${ }^{6}$ have demonstrated that $8 \mathrm{mg}$ ondansetron was effective in treating IT or epidural morphine-induced pruritus. Another study ${ }^{7}$ demonstrated that the prophylactic use of $8 \mathrm{mg}$ of ondansetron significantly reduced the incidence of IT morphine-induced pruritus. Gurkan and Toker $^{8}$ have shown that $8 \mathrm{mg}$ of prophylactic ondansetron reduced the incidence of IT fentanylinduced pruritus. However, a recent study ${ }^{16}$ suggested that $8 \mathrm{mg}$ ondansetron did not prevent IT narcotic-induced itching (morphine-sufentanil) after Cesarean delivery. Our study presents similar results with IT sufentanil in outpatient surgery.

In summary, the important findings are as follows:

l) prophylactic ondansetron $(8 \mathrm{mg} i v)$ did not reduce the incidence of pruritus in patients receiving IT sufentanil for ambulatory surgery;

2) pruritus developed with the same intensity in both groups.

\section{Acknowledgements}

The authors wish to express their appreciation to Dr. S. Rabito, Section Chair, Anesthesia Research, for her helpful advice and review of the manuscript. The authors also thank Dr. R. Behnia, Chairman, Dr. Harrison, Floor Coordinator, and Dr. R. Igic, Scientific Officer, Department of Anesthesiology and Pain Management, for their assistance. We also want to thank all the attending physicians, residents, and CRNAs whose cooperation made this study possible.

\section{References}

1 Chaney MA. Side effects of intrathecal and epidural opioids. Can J Anaesth 1995; 42: 891-903.

2 Kam PC, Tan KH. Pruritus-itching for a cause and relief? Anaesthesia 1996; 51: 1133-8.

3 Szarvas S, Harmon D, Murphy D. Neuraxial opioidinduced pruritus: a review. J Clin Anesth 2003; 15: 234-9.

4 Waxler B, Mondragon S, Patel S, Nedumgottil K. Intrathecal lidocaine and sufentanil shorten postoperative recovery after outpatient rectal surgery. Can J Anesth 2004; 51: === .

5 Ko MC, Naughton NN. An experimental itch model in monkeys. Characterization of the intrathecal morphineinduced scratching and antinociception. Anesthesiology 2000; 92: 795-805.

6 Borgeat A, Stirnemann HR. Ondansetron is effective to treat spinal or epidural morphine-induced pruritus. Anesthesiology 1999; 90: 432-6.

7 Yeh HM, Chen LK, Lin CJ, et al. Prophylactic intravenous ondansetron reduces the incidence of intrathecal morphine-induced pruritus in patients undergoing cesarean delivery. Anesth Analg 2000; 91: 172-5.

8 Gurkan $\Upsilon$, Toker $K$. Prophylactic ondansetron reduces the incidence of intrathecal fentanyl-induced pruritus. Anesth Analg 2002; 95: 1763-6.

9 Thomas DA, Williams GM, Iwata K, Kenshalo DR Jr, Dubner R. Multiple effects of morphine on facial scratching in monkeys. Anesth Analg 1993; 77: 933-5.

10 Thomas DA, Williams GM, Iwata K, Kenshalo DR Jr, Dubner $R$. The medullary dorsal horn. A site of action of morphine in producing facial scratching in monkeys. Anesthesiology 1993; 79: 548-54.

11 Hamon M, Gallissot MC, Menard F, Gozlan H, Bourgoin S, Verge D. $5-\mathrm{HT}_{3}$ receptor binding sites are capsaicin-sensitive fibres in the rat spinal cord. Eur J Pharmacol 1989; 164: 315-22.

12 Waeber C, Dixon K, Hoyer D, Palacios JM. Localisation by autoradiography of neuronal $5-\mathrm{HT}_{3}$ receptors in the mouse CNS. Eur J Pharmacol 1988; 151: 351-2.

13 Scott PV, Fischer HB. Spinal opiate analgesia and facial pruritus: a neural theory. Postgrad Med J 1982; 58 : 
531-5.

14 Andrew D, Craig AD. Spinothalamic lamina I neurons selectively sensitive to histamine: a central neurol pathway for itch. Nat Neurosci 2001; 4: 72-7.

15 Ben-David B, DeMeo PJ, Lucyk C, Solosko D. Minidose lidocaine-fentanyl spinal anesthesia in ambulatory surgery: prophylactic nalbuphine versus nalbuphine plus droperidol. Anesth Analg 2002; 95: 1596-600.

16 Yazigi A, Chalhoub V, Madi-Jebara S, Haddad F, Hayek $G$. Prophylactic ondansetron is effective in the treatment of nausea and vomiting but not on pruritus after cesarean delivery with intrathecal sufentanil-morphine. J Clin Anesth 2002; 14: 183-6. 